\title{
Comentário l:
}

\section{Menos certezas, mais vozes: o gesto curatorial frente a novas demandas sociais}

\section{Comment l:}

Less certainties, louder voices: the curatorial gesture in the face of new social demands

\section{CRISTINA MENEGUELLO'}

https:/ / orcid.org/0000-0003-1833-0107

Universidade Estadual de Campinas / Campinas, SP, Brasil

No verão de 1984, durante uma atividade de extração de turfa na região pantanosa de Lindow, perto da cidade inglesa de Manchester, foi descoberto o esqueleto de um homem. A polícia foi chamada, mas a datação por radiocarbono indicou que se tratava dos restos mortais de um homem de mais de 2 mil anos. Um grupo de cientistas e arqueólogos do British Museum determinaram que esse homem havia sido "triplamente" assassinado: recebera um golpe na cabeça, fora (provavelmente) garroteado e tivera sua garganta cortada. Eram os vestígios de um corpo assassinado, talvez ritualmente.

$\bigcirc$ "Homem de Lindow", como passou a ser conhecido, virou objeto de pesquisa, tema de reportagens e - o que nos interessa aqui - de três diferentes exposições museológicas, que expressam claramente a alteração nas últimas décadas das sensibilidades e dos debates sobre museografia e narrativa expográfica. Se à época de seu achado os debates giravam em torno de quem fora, como e quando vivera o homem de Lindow (se em 1 d.C. ou no período da ocupação romana em Manchester), nos anos 2000 os mesmos vestígios foram

\begin{abstract}
1. Graduada e mestra em história pela Universidade Estadual de Campinas (Unicamp), com doutorado sanduíche na Universidade de Manchester, obtendo o título de doutora na Unicamp. Realizou estágio de pós-doutoramento na Universidade de Veneza (IUAV), Itália, e na Universidade de Coimbra, Portugal. É docente em regime de dedicação exclusiva do Departamento de História da Unicamp, atuando nos cursos de História e de Arquitetura e Urbanismo E-mail: <cmeneguello@ gmail.com>.
\end{abstract}


2. Cf. Brooks e Rumsey (2007).

3. Randerson (2007). Recentemente os museus britânicos de história natural, o British Museum, o Leicester Museum e o Manchester Museum, entre outros, vêm sendo confrontados pelo Council of British Druid Orders (Conselho das Ordens Druidas/Celtas), que insistem na devolução de restos mortais encontrados em solo inglês e empreendem há anos negociações por ressepultamentos com o English Heritage e o National Trust. O problema se agiganta se considerarmos que apenas o Museu de História Natural, em Londres, guarda cerca de 20 mil restos mortais humanOs (BROOKS; RUMSEY, 2007), e que, em 1998, O Museu de Londres, na exposição "London Bodies", revelou uma coleção de mais de 18 mil esqueletos humanos de seu departamento de arqueologia.

4. No link para o artigo de Barbara O'Brien (2010) é possível assistir a um vídeo da campanha, no qual inocência e gosto duvidoso se mesclam e crianças trajando uma camiseta com o que seria a reconstituição do rosto do Homem de Lindow entoam a canção "Lindow Man we want you back again" [Homem de Lindow queremos você de volta]. utilizados no debate sobre questões éticas relacionadas à exibição de restos mortais, resultando em diretivas para os museus ingleses. ${ }^{2}$

Não se trata, aqui, de adentrar a polêmica sobre a exposição de vestígios humanos em museus, muito bem abordada pelos museum studies e pelos estudos fronteiriços entre ética e antropologia - ainda que o Museu Paulista tenha, também, seu quinhão fetichista de cachos e madeixas em exposição e que cada objeto que sobrevive a seu proprietário original reative reflexões sobre a pessoalidade dos vestígios.

O foco, outrossim, é observar as escolhas em mutação na exibição do Homem de Lindow, "emprestado" pelo British Museum e levado para o Manchester Museum por três vezes: em 1987, numa exposição vastamente baseada nos achados forenses sobre o corpo; em 1991, numa espécie de repetição ampliada da anterior; e, finalmente, na controversa exibição em 2008-2009. No terceiro caso, já não havia consenso sequer sobre a "tripla morte" do homem, encontrado em antiga terra comunal. Grupos que se professam pagãos socialmente marginalizados haviam adentrado o debate reivindicando o direito a re-enterrar aqueles que consideram "seus mortos", em 2007, exigindo a devolução dos ossos do Homem de Lindow para um novo sepultamento. ${ }^{3}$

A exposição de 2008-2009 admitiu que as reações dos não especialistas aos restos do Homem de Lindow, em especial da população local, nunca haviam sido levadas a sério. De fato, em 1987, quando o corpo foi enviado para o British Museum, houve uma intensa campanha local para "repatriar" o Homem de Lindow, devolvendo-o a Manchester. Capitaneada por Barbara O'Brien, que então trabalhava na TV Granada, a campanha teve uma canção gravada por crianças e recebeu grande adesão popular, ainda que não secundada por nenhum museu, arqueólogo ou especialista. ${ }^{4}$ Atenta a essa memória da exclusão dos não especialistas, a exposição, aberta em abril de 2008, começara a ser planejada no ano anterior, em reuniões com membros da comunidade que expressavam seus desejos e expectativas em relação à nova exibição do corpo "expatriado".

Na exposição de 2008-2009 abdicou-se das explicações de contexto e abriram-se espaços para que o testemunho entrasse nas narrativas: ganharam protagonismo os depoimentos gravados e escritos de um cientista forense, um arqueólogo, dois curadores de museus, um trabalhador da turfa, uma pessoa da comunidade de lindow e um pagão. Vieram para o primeiro plano não mais o corpo encontrado, mas os processos desencadeados por seu achamento. Contrariando as sugestões dos entrevistados para que fosse criado um enorme painel cenográfico representando a paisagem onde o Homem de Lindow havia sido encontrado lo que 
reativava os apelos de pertencimento e de retorno para casa do espécime), os restos foram expostos numa caixa de vidro, semienterrados na turfa, como se "reencontrados" novamente por cada espectador. Uma outra caixa, para que os visitantes deixassem "oferendas" para o corpo - solução expositiva que aborreceu a muitos - gerou para o museu de Manchester uma enorme coleção de objetos, à qual vieram se somar milhares de fichas de avaliação preenchidas pelos visitantes. Esses objetos de oferta e as fichas tornaram-se, por sua vez, parte do acervo do museu, num desejo de que sejam estudadas no futuro - a se imaginar que as pesquisas futuras serão movidas pelos mesmos interesses que nos tocam.

Na nova narrativa da exposição havia menos certezas e mais vozes. A decisão de priorizar a polivocalidade ultrajou parte do público, ora descontente com o que identificou como falta de dados factuais, ora insatisfeito com a horizontalidade de ter um depoimento de um "pagão" ao lado do de um especialista forense ou arqueólogo. Conforme o responsável pela exposição, "o corpo foi deliberadamente divorciado de qualquer interpretação; os visitantes tinham que formar sua opinião a partir das informações expostas. $\bigcirc$ Museu tomou o cuidado de evitar sugerir que qualquer das interpretações pudesse ser vista como de autoridade". ${ }^{5}$ Em análise posterior, o mesmo curador observou que boa parte da reação negativa veio - em blogs, comentários na internet e nas avaliações deixadas por escrito - de pessoas que buscaram reencontrar a exposição que haviam visto em 1991 ou que esperavam uma narrativa de autoridade e explicação por parte do museu. Os entrevistados de 2007, consultados após a exposição ficar pronta, disseram-se decepcionados ao ver a forma final que suas sugestões haviam tomado; e especialistas em museus criticaram as escolhas porque, quando o museu desiste de fazer uma narrativa sobre aquilo que é exposto, pode fazer da visita uma experiência de pura desorientação. ${ }^{6}$

Considero o caso do Homem de Lindow um bom exemplo das incertezas que os objetos de acervo musealizados podem gerar, e a escolhi propositalmente para pontuar que tais incertezas não são uma peculiaridade dos objetos dos ditos museus de história. $\bigcirc$ caso, aparentemente distante no tempo e na geografia das reflexões apresentadas por Vânia Carneiro de Carvalho, Paulo César Garcez Marins e Solange Ferraz de Lima no excelente ensaio "Curadoria em museus de história", traz à nossa atenção as percepções em transformação sobre quais documentos do passado um museu pode arquivar e mobilizar, segundo a perspectiva de que objetos e imagens do passado não são apenas evidência que possa comprová-lo, mas uma "dimensão documental pela qual a sociedade pode ser compreendida" ?

$\bigcirc$ texto herda de seus três autores duas qualidades inegáveis. A primeira, a de ser produzido por especialistas que conhecem seu métier e a literatura
5. Sitch (2009, p. 2, tradução nossa).

6. Sitch (2010, p. 54, tradução nossa).

7. Carvalho, Marins e Lima (2021, p. 13). 
associada, o que permite um histórico embasado das práticas curatoriais em museus de história europeus e brasileiros, num esforço admirável de síntese e informação. A segunda qualidade se refere ao fato de que os autores conhecem o espaço do Museu Paulista a partir de suas entranhas: suas reflexões não são comentários formais ou distanciados, mas de sabedores das rotinas, escolhas e exclusões que a prática da curadoria, do arquivo e da exposição exigem. Nesse sentido, o texto também reafirma a trajetória intelectual de seus autores, as pesquisas e reavaliações gestadas dentro da própria prática profissional, em seus textos publicados /como a análise da produção iconográfica em telas sobre o passado paulista a partir da coleção fotográfica) ou na orientação de trabalhos (caso das políticas de aquisição de acervos, que primeiro se abriram ao cotidiano e à cultura material e, depois, aos ausentes). É salutar que pessoas que tomam parte das decisões de cura consigam refletir sobre as políticas que direcionam seu trabalho, ainda mais quando estão sob as lógicas burocráticas e de atribuição de funções que norteiam a universidade pública, na dança dos cargos e das verbas, em meio aos desafios gigantescos do restauro e da reinauguração da instituição.

Por outro lado, algumas afirmações no texto beiram a provocação, como afirmar que as relações dos objetos nos museus de história no século XX seguem atravessadas por uma concepção oitocentista até, pelo menos, a década de 1980, ${ }^{8}$ ignorando toda a nova museologia; ou a arriscada ênfase na potência explicativa dos objetos em si, sem estarem necessariamente associados a narrativas. Os acervos serão sempre fruto de explicações e narrativas a respeito deles - mesmo quando se trata de objetos aparentemente "reprodutíveis" - e a decisão curatorial sobre quais coleções abarcar e quais descartar é, em si, um ato de colecionismo informado. As narrativas assumidas sobre o passado - se gloriosas, se traumáticas, se contestadoras dos cânones da historiografia - têm a potencialidade de democratizar as vozes e as reapresentações de sujeitos históricos, e pouca diferença faz se os objetos são mobilizados pela narrativa de um museu de história, de ciências ou de arte. Nenhum documento ou objeto tem valor intrínseco para além da expressão de um certo consenso social. Assim, a especificidade de um museu histórico não reside necessariamente em sua filiação a outros museus de história, definidos pelas narrativas dos Estados-nação e da invenção de identidades e tradições, aos moldes do século XIX. Sua especificidade está na transitoriedade de um passado que, tendo existido, só pode ser entendido pela narrativa que suas sobrevivências mobilizam. Se concordamos, pois, que as forças em jogo nos acervos de um museu que se autodeclara histórico também estão em tensão para os ditos objetos de arte, antropológicos ou científicos, é preciso romper com o mito de fundação de Alexandre Lenoir como a origem dos museus históricos e das 
exibições históricas. Interessa mais ao espírito historiador a dimensão trágica da narrativa civilização versus barbárie, na qual Lenoir inscreve-se como herói - essa sim uma narrativa histórica que se converte em evento no qual "a história da arte de um povo não se dissocia de sua história política". 9

Seguramente, vestígios salvos da destruição guardam a ferida do trauma, diferentemente do caso dos acervos doados por causa de desejos de glorificação póstuma. Ainda assim, ao Museu Paulista, com sua dupla origem de monumento e museu, ${ }^{10}$ foi adicionada a condição de museu universitário, dimensão que merece ser mais bem enfatizada. Um museu que pertence a uma universidade pode propor experimentações teóricas e historiográficas inéditas por meio de suas escolhas narrativas e expositivas. Sua coleção deve alimentar a pesquisa acadêmica e o interesse do público, ainda mais se, nesse caso em especial, não se trata de um museu que coletou apenas a história, os materiais e os artefatos da própria universidade, mas que pode desafiar os currículos estabilizados. $\bigcirc$ museu universitário pode encarar desafios culturais de desconstruir as narrativas históricas e até mesmo interferir nas narrativas difundidas na educação básica e aos públicos mais amplos, não para gerar narrativas substitutivas às tradicionais ou excludentes, mas como espaço para a controvérsia. ${ }^{11}$

A tarefa com a qual o Museu Paulista vê-se confrontado, "às margens" das comemorações do bicentenário, reflete simultaneamente esse desejo de acolher outras vozes e corrigir apagamentos na narrativa da história, além de redimensionar a própria prática do colecionar e do expor. Não existe ato curatorial inocente (como parece ter ambicionado - para mencionar, pela última vez - a terceira exposição do Homem de Lindow em Manchester). A necessidade de desescolarização dos museus, tão bem apontada por Margaret Lopes ainda nos anos 1990,12 não deve desembocar na ausência da narrativa ou na mera substituição de narrativas. A decisão de propor outras histórias a partir dos vestígios permite estabelecer o passado como um jogo de encaixes e combinações, mas jamais um quebra-cabeças no qual as peças devem estar sempre no mesmo lugar para gerar uma imagem completa. Os novos arranjos das peças podem oferecer narrativas que atendam às demandas sociais de novos sujeitos históricos que reclamam visibilidade. Nesse processo, é provável que os combates narrativos das comemorações do bicentenário da independência dos Estados Unidos, em 1976, ou da Revolução Francesa, em 1989, tenham muito a ensinar. $\bigcirc$ que narrar, às vésperas do bicentenário de uma independência, cuja nomeação já prescinde das diferentes temporalidades da independência no território brasileiro, que não necessariamente coincidem com 1822? Em 2022, num momento em que as falas sobre a "brasilidade" e a pátria estarão profundamente disputadas, num ano de
9. Lenoir (1811, p. 2, tradução nossa).

10. Cf. Brefe (2003).

11. Cf. Livingstone, Hartz e Rothermel (2016).

12. Lopes (1991). 
13. Araujo (2017, p. 192).

14. Ibid., p. 213.

15. Cf. Turin (2018).

16. Carvalho, Marins e Lima, op. cit., p. 13. eleições e de aprofundamento de projetos políticos com laivos autoritários e fascistas, a batalha por imagens, memórias e discursos autorizados será intensa.

Por essa razão, reporto-me aqui à expressão cunhada por Araujo, que sugeriu compreender o historiador como curador e a historiografia como capaz de alargar nossa experiência e conhecimento da história, pontuando que, "no lugar de se pensar apenas como um centro irradiador, o campo historiográfico poderia projetar-se como espaço de acolhimento e convergência crítica da pluralidade de histórias", funções que "não são contraditórias, nem excludentes, embora não possam ser tomadas como idênticas". ${ }^{13}$ Nesse circuito, o historiador desenvolve uma nova e distinta função social, aparecendo como "curador de histórias", num processo em que as memórias ativadas podem ser mais importantes do que o resultado, em que novas formas de autoria, compartilhadas e colaborativas na produção de conhecimento, podem ser protagonistas. "A curadoria de histórias como um espaço de promoção, seleção, edição e reapresentação de histórias socialmente distribuídas e compartilhadas deve, entretanto, responder ao desafio de decidir que histórias curar." 14

historiador como curador é uma possível resposta às bibliografias e ações indiferentes às demandas dos coletivos sociais, sujeitos que exigem que suas presenças e epistemologias estejam contempladas, não apenas como "novos assuntos", mas estruturalmente na construção de conhecimento. Desafiar autoridades e horizontalizar os testemunhos é importante. Mas qual é o lugar, nesse universo, para a autoridade do historiador? Esse local encontra-se, na atualidade, numa disputa não muito diversa da que vigorou no século XIX com a voga do romance histórico, quando o esforço para construir a autoridade do historiador profissional versus o historiador amador (historiógrafos, compiladores de fatos, memorialistas) os levou à arena pública e à profissionalização. Em meio à perda de terreno do ensino de história no Ensino Médio, perpetrada pelo governo Temer em 2017, ao esvaziamento das narrativas autorizadas e ao espaço disputado com youtubers e curiosos (muitos politicamente mal-intencionados), a narrativa da história em outros espaços, comumente chamados de não formais, torna-se ainda mais necessária. O historiador mais uma vez parece ter que reafirmar sua autoridade para formular suas hipóteses sobre o passado. ${ }^{15}$

Como apontado em "Curadoria em museus de história", a história das coisas e dos objetos entendidos como objetos sociais pode "aprofundar a compreensão das tensões sociais e da pluralidade de sujeitos, nas múltiplas temporalidades e em uma história não linear", ${ }^{16}$ permitindo compreender a historicidade da cultura material da sociedade brasileira e paulista. Nesse sentido, a experiência curadora da história não está restrita à escrita, ao ensino ou ao 
museu, nem à mera ampliação dos públicos, mas se relaciona com a "reivindicação de uma cidadania que quer ser pensada como polo ativo na produção de uma historiografia socialmente distribuída, ou seja, da democratização das condições de escrita e apresentação de histórias". ${ }^{17}$

Aqui é necessário extrapolar regimes discursivos preestabelecidos e que não foram capazes de responder às demandas da sociedade; na obtenção dos acervos, em sua curadoria e nas estratégias previstas para a interação entre esses acervos e o público (interessado ou desinteressado) reside a possibilidade de interferir nas narrativas cristalizadas do passado heroicizado. Entretanto, por mais ilógicos, classistas, excludentes e alinhados a discursos de dominação que sejam os acervos, eles são, a despeito de sua natureza e por causa dela, históricos. As perguntas sobre o gesto curatorial são as perguntas do historiador em seu trato com o passado.

Paul Ricoeur já indicara que não há objetos se não houver um sujeito capaz de conhecê-los. Se o objetivo do historiador não é o passado em si, mas os homens no tempo, tal como na fórmula proposta por Marc Bloch, as experiências manifestas por meio dos acervos estão ancoradas nesses vestígios, que são para as ciências históricas o que a chamada observação direta é para as ciências naturais, um intermediário que permite acessar o objeto. Se a observação histórica ocorre de modo indireto, mediada por fontes e testemunhos, isso não diminui a cientificidade da objetividade histórica. Todavia, "observar não significa nunca registrar um fato bruto". ${ }^{18}$ Quando analisou a obra de Bloch, Ricoeur apontou que o historiador estabelece continuidades para explicar acontecimentos; comparações para explicar os "outros" - existências que foram abolidas (a servidão, o feudalismo) - em uma linguagem atual que não mais se refere a elas. ${ }^{19} \mathrm{O}$ historiador lança ao documentoobjeto perguntas e hipóteses porque busca respostas. Nessa operação o método historiográfico institui determinados vestígios deixados pelo passado como documentos, atribuindothes uma significação que não está destituída da subjetividade do historiador. Nas representações que cria a respeito do passado, o historiador não é apático (desprovido de pathos); ele anseia pela verdade. $\bigcirc$ passado é por ele ordenado, ciente de que não narra os fatos brutos, não os revive e não os sintetiza em sua totalidade. ${ }^{20}$

Ricoeur também apontou que o historiador faz parte da história, não no sentido imediato de que o passado antecede seu presente, mas no sentido de que os homens do passado fazem parte da mesma humanidade: "a história é, portanto, uma das maneiras pelas quais os homens 'repetem' seu pertencimento à mesma humanidade; ela é um setor de comunicação de consciências". ${ }^{21}$ Nesse anseio por não faltar ao encontro marcado com as gerações do passado, (como apontou Benjamin em suas Teses), ${ }^{22}$ é necessária a imaginação. A escrita da história-aqui
17. Araujo, op. cit., 206.

18. Ricoeur (1968, p. 25).

19. Cf. Mendes (2019).

20. Ricouer (2007).

21. Ibid., p. 32.

22. Benjamin, Tese II. (223 005). 
comparada à curadoria da história - é uma prática ativa, e não descritiva. Aquele que entra em contato com os acervos "curados" e traduzidos pelo museu deseja a experiência que o instiga, mas também na qual se vê representado, nem que pelo desafio de encontrar o totalmente diverso. A legibilidade torna visível o acontecimento e as relações que os objetos testemunham. Disso depende a narrativa sobre os sujeitos do passado e se seus atos serão compreendidos dentro de estruturas amplas que dão sentido ou explicam seus atos e gestos. Caso contrário, o que será narrado estará na forma de estruturas como "escravidão", "bandeiras", "processo de independência", que são existências discursivas cunhadas para auxiliar a compreensão do passado e que, quando utilizadas, pretendem cobrir uma série de lógicas e explicações que se imagina serem consensuais. Na curadoria dos museus de história as fases do arquivo, da pesquisa e da escrita, propostas por Ricoeur, podem se repetir transfiguradas: o arquivo transforma-se na criação do acervo; a pesquisa, nas decisões sobre as explicações históricas; e a escrita/narração, enfim, transmuta-se nas exposições. A curadoria da história, ao criar representações que sejam polivocais e éticas, evitando uma mera horizontalidade que pode aplainar narrativas irreconciliáveis, pode ampliar a capacidade de estranhamento, empatia, compreensão e cidadania. 


\section{REFERÊNCIAS}

LIVROS, ARTIGOS E TESES

ARAUJO, Valdei Lopes de. O direito à história: o(a) historiador(a) como curador(a) de uma experiência histórica socialmente distribuída. In: GUIMARÃES, Géssica; BRUNO, Leonardo; PEREZ, Rodrigo (orgs.). Conversas sobre o Brasil: ensaios de crítica histórica. Rio de Janeiro: Autografia, 2017. p. 191-216.

BENJAMIN, Walter. Teses sobre o conceito da história. In: LÖWY, Michael. Alarme de incêndio: uma leitura das Teses sobre o Conceito de História. São Paulo: Boitempo, 2005. p. 48-53.

BREFE, Ana Cláudia Fonseca. História nacional em São Paulo: o Museu Paulista em 1922. Anais do Museu Paulista, São Paulo, v. 10-11, n. 1, p. 79-103, 2003. Doi: <https://doi.org/10.1590/ S0101-47142003000100006>.

BROOKS, Mary; RUMSEY, Claire. The body in the museum. In: CASSMAN, Vicki; ODEGAARD, Nancy; POWELL, Joseph (eds.). Human remains: guide for museums and academic institutions. Oxford: AltaMira, 2007. p. 261-289.

CARVAlHO, Vânia Carneiro de; MARINS, Paulo César Garcez; LIMA, Solange Ferraz de. Curadoria em museus de história. Anais do Museu Paulista, São Paulo, v. 29, p. 1-24, 2021. Doi: <https://doi.org/10.1590/1982-02672021v29e40>.

LENOIR, Alexandre. Histoire des arts en France, prouvée par les monumens, suivie d'une description chronologique des statues en marbre et en bronze, bas-reliefs tombeaux des hommes et des femmes célèbres, rénuis au Musée Impérial des Monumens Français. Paris: [s. n.], 1811. Disponível em: <https://bit.ly/3gcV1Jl>. Acesso em: 6 jun. 2021.

LIVINGSTONE, Phaedra; HARTZ, Jill; ROTHERMEL, Barbara. A formidable forum: university museums embrace controversy. University Museums and Collections Journal, [s. l.], v. 8, p. 23-28, 2016.

LOPES, Maria Margaret. A favor da desescolarização dos museus. Educação E Sociedade, Campinas, n. 40, p. 443-455, 1991.

MENDES, Breno. A representação do passado histórico em Paul Ricoeur. Porto Alegre: Fi, 2019.

O'BRIEN, Barbara. Do you remember the Lindow Man Campaign. Wilmslow, Cheshire, 2 nov. 2010. Disponível em: <https://bit.ly/3x4WfNw>. Acesso em: 6 jun. 2021.

RANDERSON, James. Give us back our bones, pagans tell museums. The Guardian, London, 5 fev. 2007. Disponível em: <https://bit.ly/3x4WsQO>. Acesso em: 6 jun. 2021. 
RICOEUR, Paul. A memória, a história e o esquecimento. Campinas: Editora Unicamp, 2007.

RICOEUR, Paul. História e verdade. Rio de Janeiro: Forense Universitária, 1968.

SITCH, Bryan. Courting controversy: the Lindow Man exhibition at the Manchester Museum. University Museums and Collections Journal, [s. l.], v. 2, p. 51-54, 2009

SITCH, Bryan. Museum consultation or confrontation? Lindow Man, a bog body mystery. In: The new museum community: audiences, challenges, benefits. Edinburgh: Museums Etc, 2010. p. 366-393.

TURIN, Rodrigo. Entre o passado disciplinar e os passados práticos: figurações do historiador na crise das humanidades. Tempo, Niterói, v. 24, n. 2, p. 186-205, 2018. Doi: <https://doi. org/10.1590/TEM-1980-542X2018v240201>.

Artigo apresentado em: 22/02/2021. Aprovado em: 01/03/2021.

\section{(cc) BY}

